Supporting Information

to

\title{
Water-Assisted Process for Purification of Ruthenium Nanomaterial Fabricated by Electron Beam Induced Deposition (EBID)
}

Markus Rohdenburg, ${ }^{a *}$ Robert Winkler, ${ }^{\mathrm{b}}$ David Kuhness, ${ }^{\mathrm{b}}$ Harald Plank $^{\mathrm{b}, \mathrm{c}, \mathrm{d}}$ and Petra Swiderek ${ }^{\mathrm{a} *}$

a University of Bremen, Institute for Applied and Physical Chemistry,

Fachbereich 2 (Chemie/Biologie), Leobener Straße / NW 2,

Postfach 330440, D-28334 Bremen, Germany

b Christian Doppler Laboratory for Direct-Write Fabrication of 3D Nano-Probes

(DEFINE), Institute of Electron Microscopy and Nanoanalysis, Graz University of Technology, Steyrergasse 17, A-8010 Graz, Austria

c Institute of Electron Microscopy and Nanoanalysis, Graz University of Technology, Steyrergasse 17, A-8010 Graz, Austria

d Graz Centre for Electron Microscopy, Steyrergasse 17, A-8010 Graz, Austria

*Corresponding author emails: m.rohdenburg@uni-bremen.de (M.R.), swiderek@unibremen.de (P.S.) 


\section{Thickness Calibration for $(\mathbf{E t C p})_{2} \mathbf{R u} / \mathrm{Ta}$}

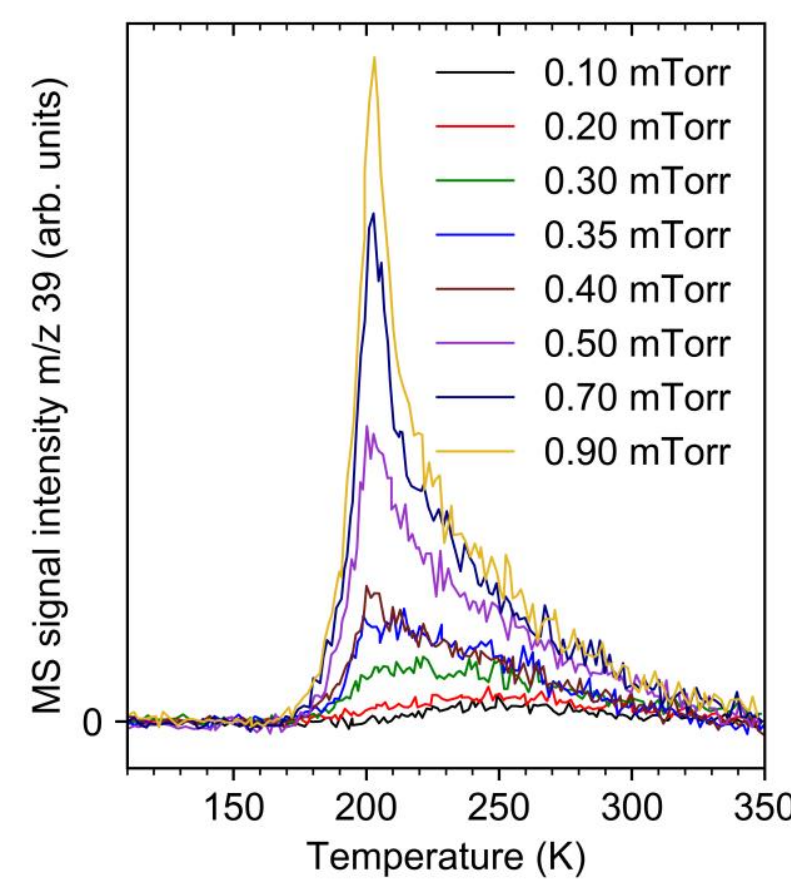

Figure S1. Thermal desorption spectra of thin layers of $(\mathrm{EtCp})_{2} \mathrm{Ru}$ recorded after dosing various amounts of vapor to the Ta sheet held at $110 \mathrm{~K} . \mathrm{m} / \mathrm{z} 39\left(\mathrm{C}_{3} \mathrm{H}_{3}{ }^{+}\right)$was chosen as a representative fragment of $(\mathrm{EtCp})_{2} \mathrm{Ru}$. The transition from the monolayer desorption signal with maximum around $250 \mathrm{~K}$ to the multilayer desorption peaking between 200 and $210 \mathrm{~K}$ occurs in the spectrum obtained for $0.30 \mathrm{mTorr}$ giving evidence that the monolayer was saturated when a vapor dose between 0.20 mTorr and $0.30 \mathrm{mTorr}$ was leaked onto the substrate. 


\section{Height Variation Experiments for Deposition of (EtCp $)_{2} R u$}
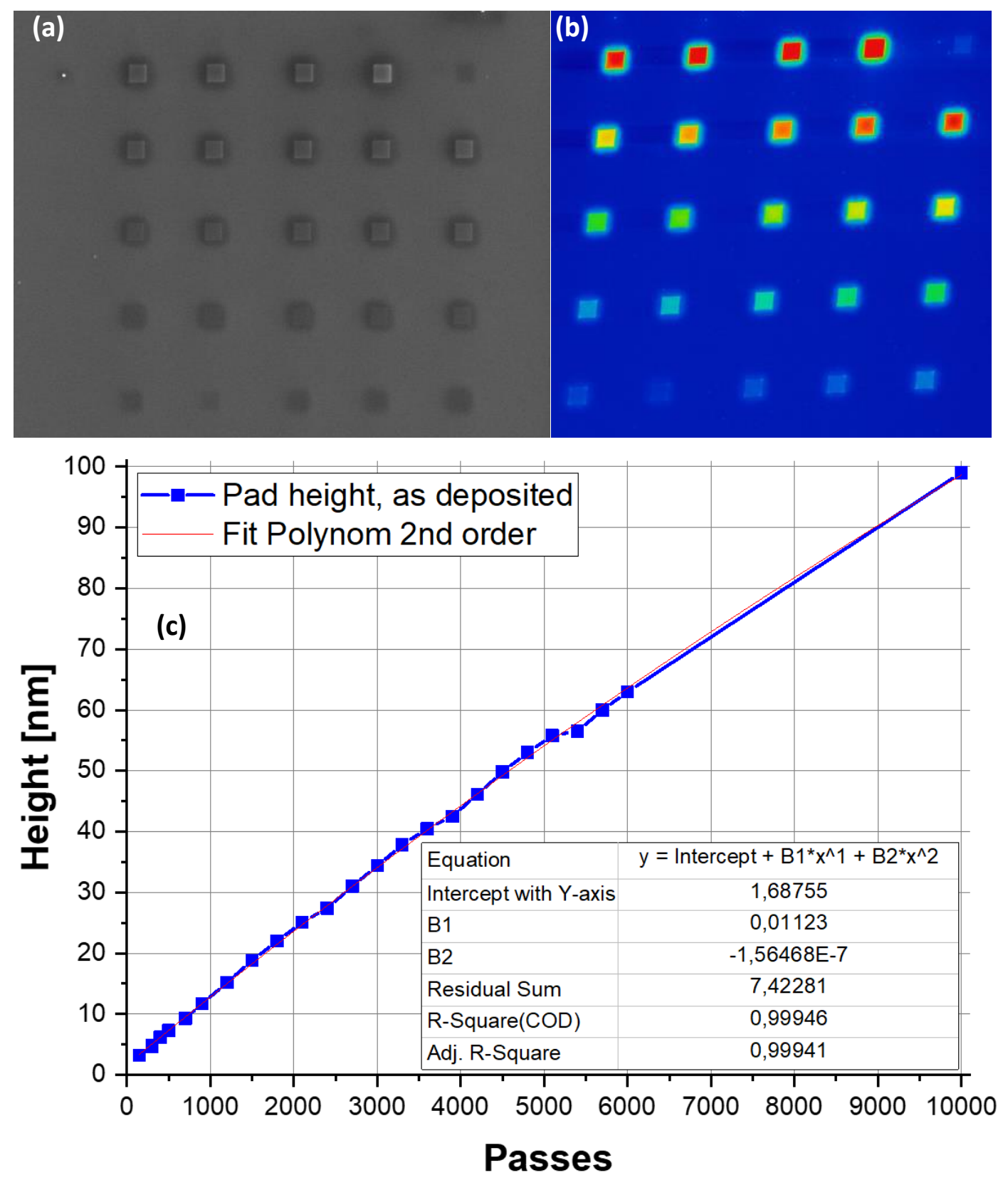

Figure S2. Growth characteristics for the deposition of $500 \times 500 \mathrm{~nm}^{2}$ square shaped pads fabricated from $(\mathrm{EtCp})_{2} \mathrm{Ru}$ : (a) SEM image of a 5 x 5 array of pads which have been deposited with a varying number of passes of the electron beam across the deposition area (range: 100-10000 passes), (b) AFM image of the same array as in (a) (blue $-0 \mathrm{~nm}$, red $-100 \mathrm{~nm}$ ), (c) plot of deposit height against number of passes. 


\section{Deposit Height Homogeneity Across Deposition Array}
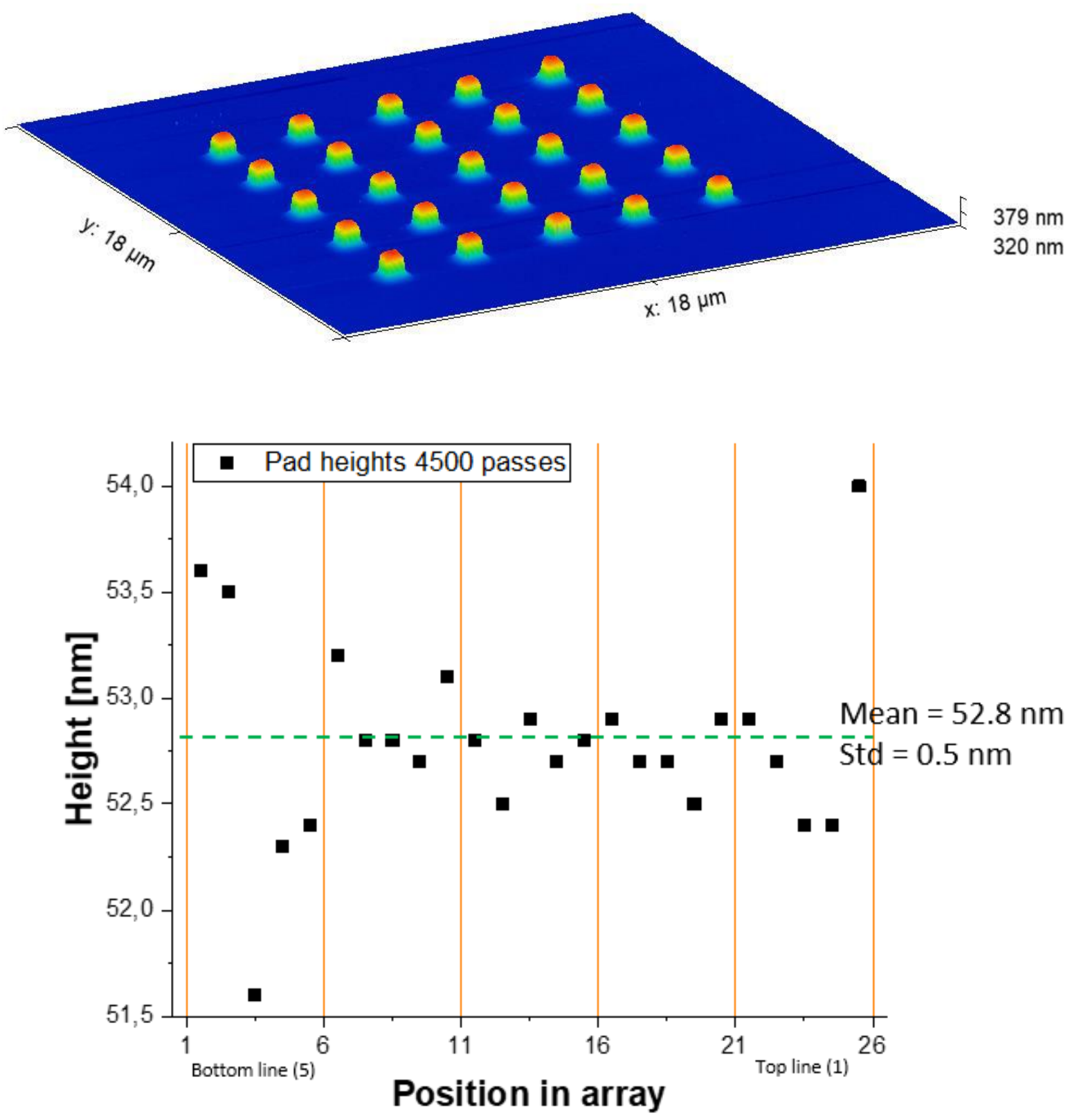

Figure S3. (a) AFM image of a $5 \times 5$ array of identically fabricated $500 \times 500 \mathrm{~nm}^{2}$ square shaped pads produced from $(\mathrm{EtCp})_{2} \mathrm{Ru}$. (b) Plot of deposit height against deposit position in the same array as depicted in (a). 


\section{CASINO Simulation of Electron Trajectories for $120 \mathrm{~nm}$ thick $(\text { EtCp })_{2}$ Ru Deposits on a Si Substrate}

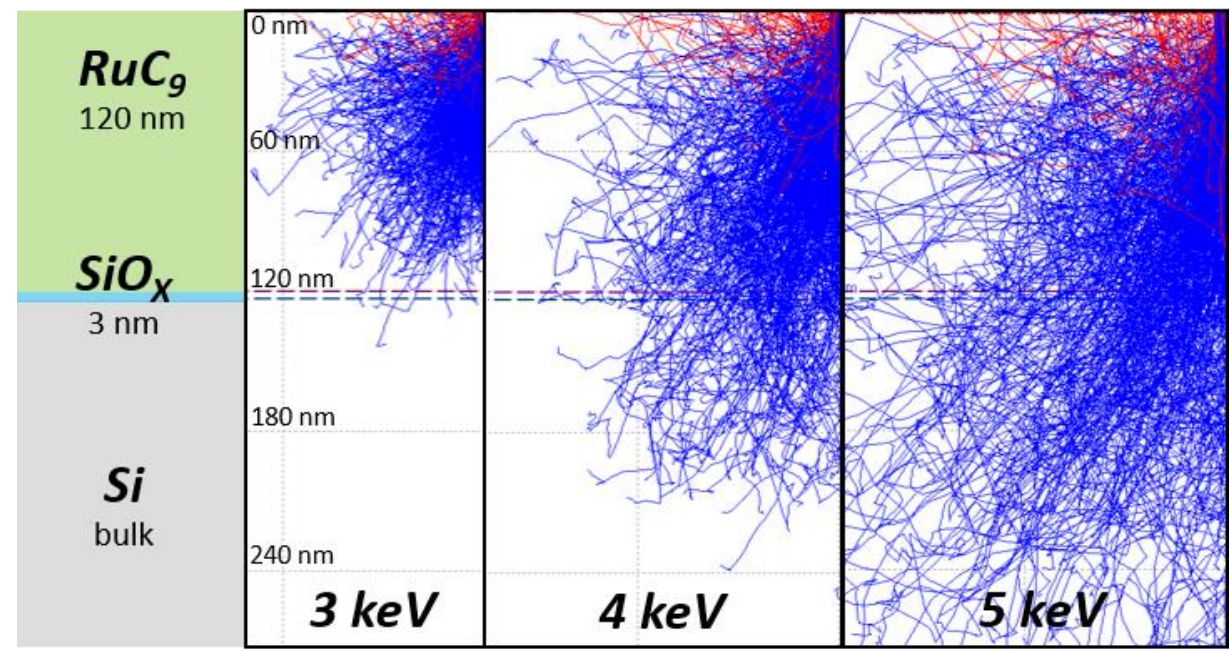

Figure S4. Simulated electron trajectories from $\mathrm{CASINO}^{\mathrm{SI1}}$ with a primary energy of $5 \mathrm{keV}$ (right), $4 \mathrm{keV}$ (middle) and $3 \mathrm{keV}$ (right) impinging on a $120 \mathrm{~nm}$ thick $\mathrm{RuC}_{9}$ deposit on a Si substrate with a native $3 \mathrm{~nm} \mathrm{SiO} 2$ layer. The employed deposit density is calculated from the weighted atomic composition, i.e. $\rho=3.2 \mathrm{~g} / \mathrm{cm}^{3}$.

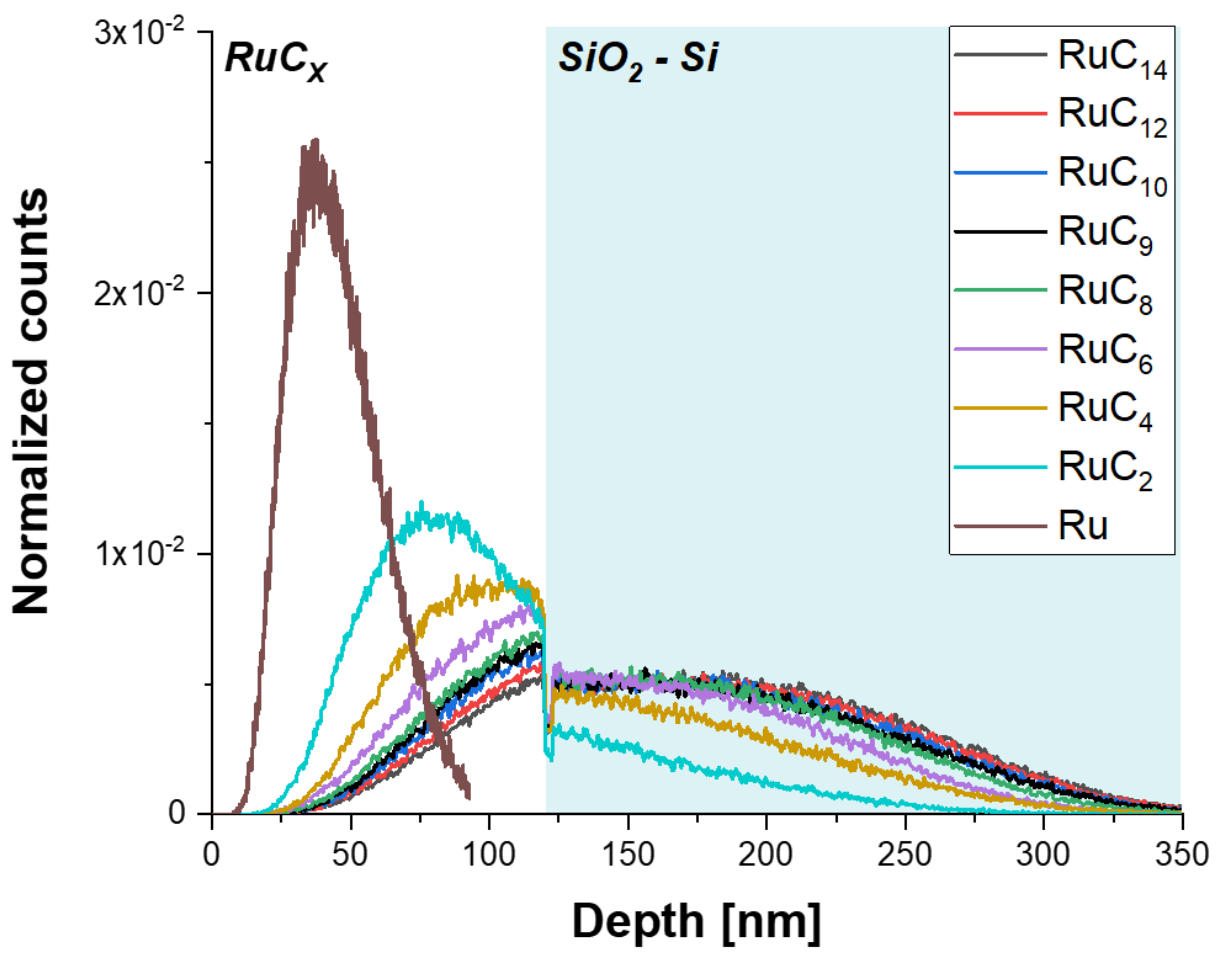

Figure S5. Penetration depth dependency of $5 \mathrm{keV}$ electrons impinging on a $\mathrm{RuC}_{\mathrm{x}}$ deposit with varying amount of carbon on top of a $\mathrm{Si}$ substrate with native $3 \mathrm{~nm} \mathrm{SiO}$ layer. $^{2}$ 


\section{SEM Images of As Deposited and Purified Pads}

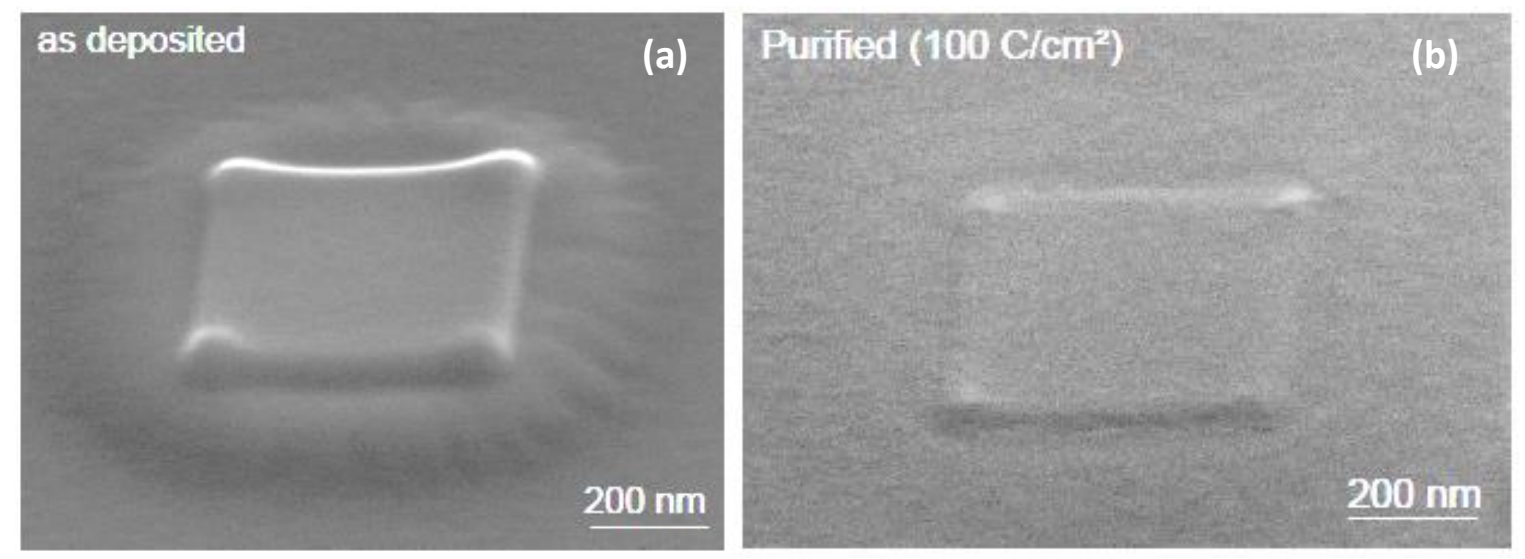

Figure S6. SEM images of (a) a pristine 500 x $500 \mathrm{~nm}^{2}$ deposit produced from (EtCp) ${ }_{2} \mathrm{Ru}$ and (b) a fully purified $\left(100 \mathrm{C} / \mathrm{cm}^{2}\right.$ at $\left.50 \mathrm{~Pa} \mathrm{H}_{2} \mathrm{O}\right)$ deposit, where the absence of cracks and / or pinholes become evident. 


\section{Purification Progress Monitored by AFM}
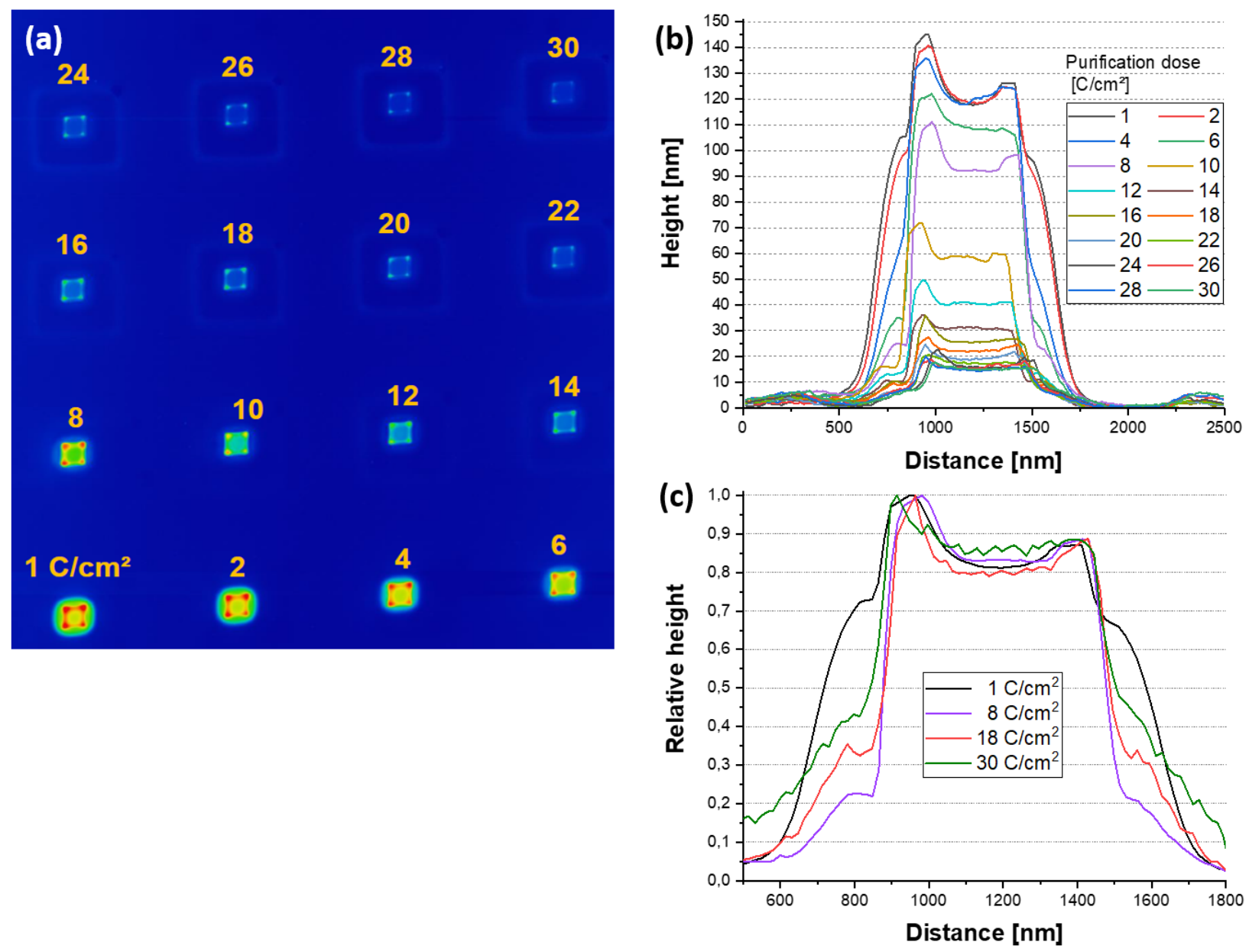

Figure S7. (a) AFM image of a $5 \times 5$ array of $500 \times 500 \mathrm{~nm}^{2}$ deposits made from $(\mathrm{EtCp})_{2} \mathrm{Ru}$ that have been purified by different electron exposures (range: $1-30 \mathrm{C} / \mathrm{cm}^{2}$ ) at a $\mathrm{H}_{2} \mathrm{O}$ pressure of $50 \mathrm{~Pa}$. (b) AFM cross sections of all 25 deposits as shown in panel (a). (c) selected AFM cross section profiles from (b) normalized to maximum height, demonstrating the 3D-shape preserving character of the purification approach. 


\section{Ruthenium Reference for EDXS}

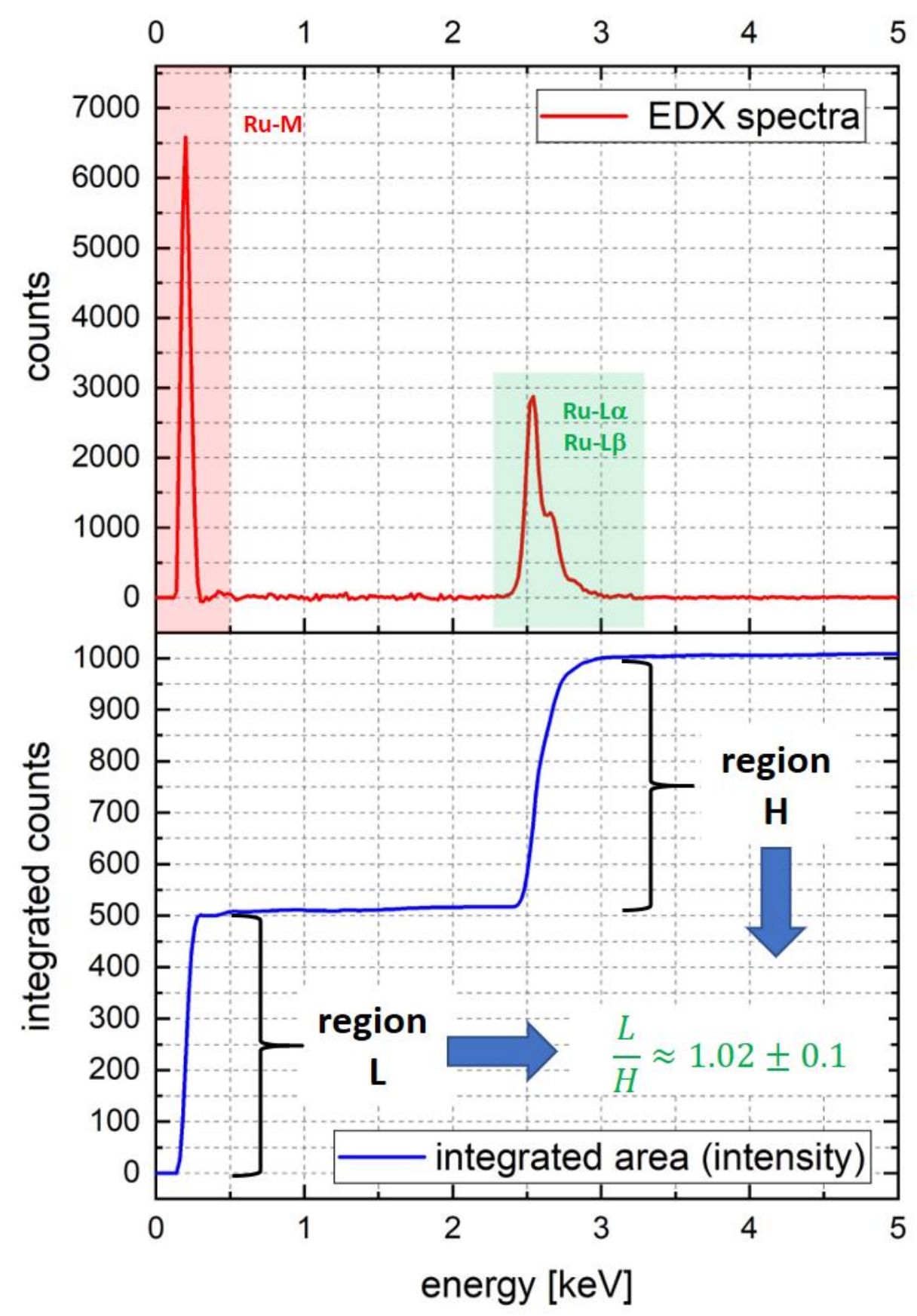

Figure S8. Ru reference. The upper graph shows a background corrected in situ EDXS spectrum of a sputter-cleaned $\mathrm{Ru}$ sample, acting as carbon-free reference. The lower graph shows the integrated peak areas, used for determination of reference peak area ratio L:H. Multiple measurements revealed a value of $1.02 \pm 0.1$, which is the target value for carbon free Ruthenium. We note that this value might change from setup to setup and has to be calibrated each time the EDXS and / or its operation parameter change. 


\section{Influence of $\mathrm{SiO}_{2}$ during Swelling}

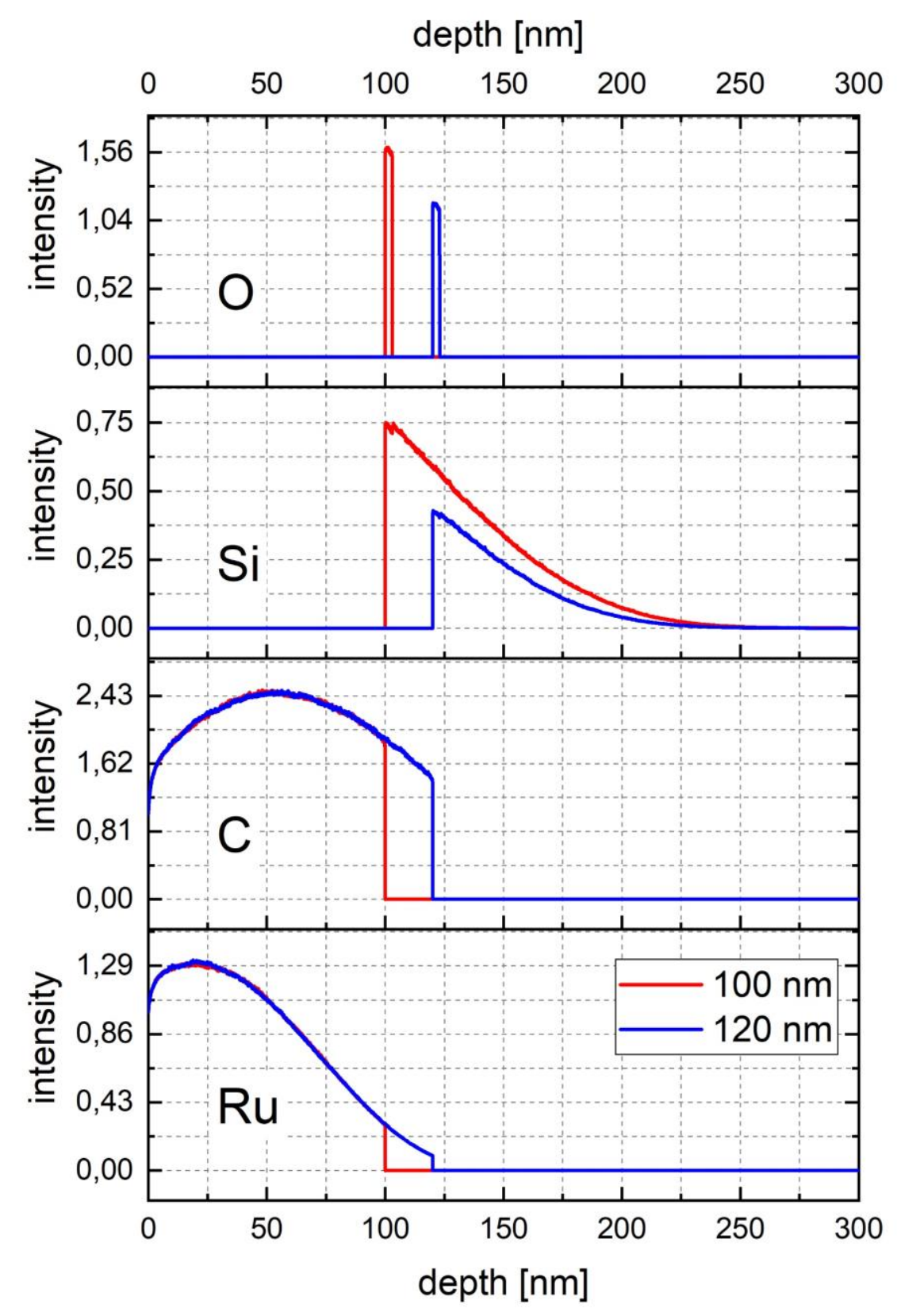

Figure S9. X-ray simulations using $\mathrm{CASINO}^{\mathrm{SII}}$ reveal the depth resolved X-ray emission intensities for oxygen, silicon, carbon, and ruthenium emitted from a $\mathrm{RuC}_{9}-\mathrm{SiO}_{2}(3 \mathrm{~nm})-\mathrm{Si}$ (bulk) stack as used for our experiments. The red curve indicates the starting $\mathrm{RuC}_{9}$ thickness of $100 \mathrm{~nm}$, while the blue curve shows the relative emission for a $120 \mathrm{~nm}$ thick $\mathrm{RuC}_{9}$ deposit, as observed after very low purification doses below $5 \mathrm{C} / \mathrm{cm}^{2}$ (see main Figure 4). Of particular relevance is the top panel for oxygen, which shows that the swelling should decrease the oxygen intensity. As this is the opposite in our experiments,

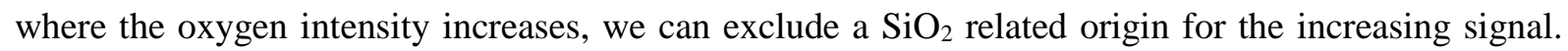
Instead, matrix modification / oxidation is a more likely process as discussed in the main text. 


\section{Ex situ EDXS Analyses}
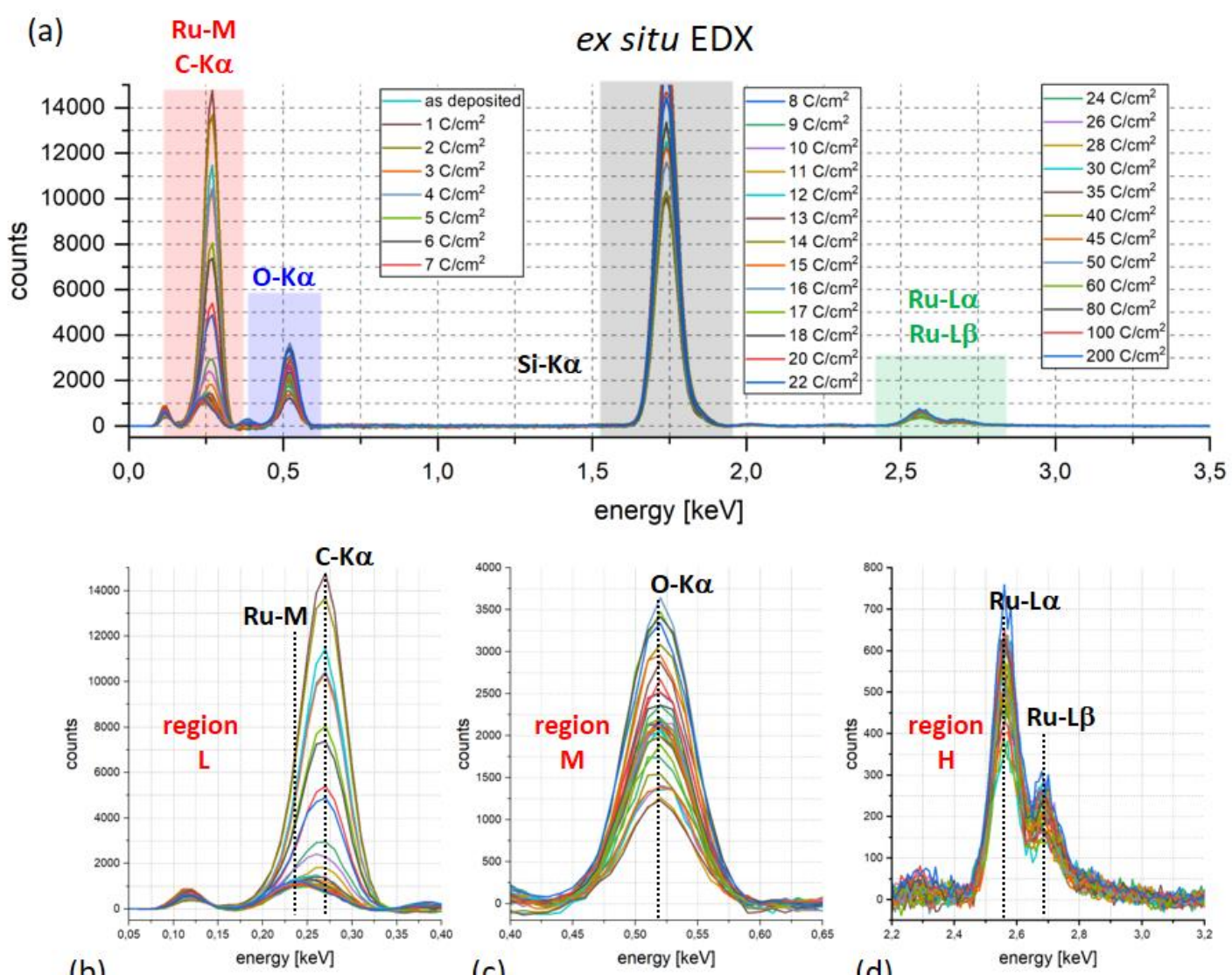

(b)

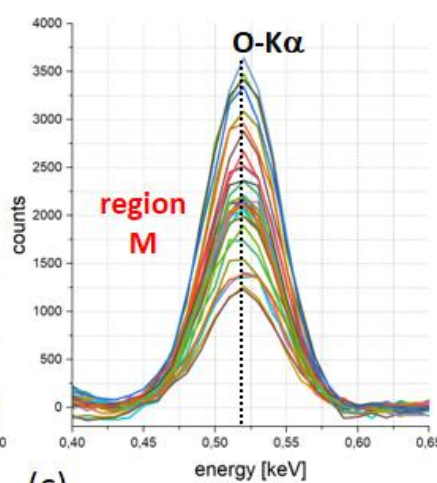

(c)

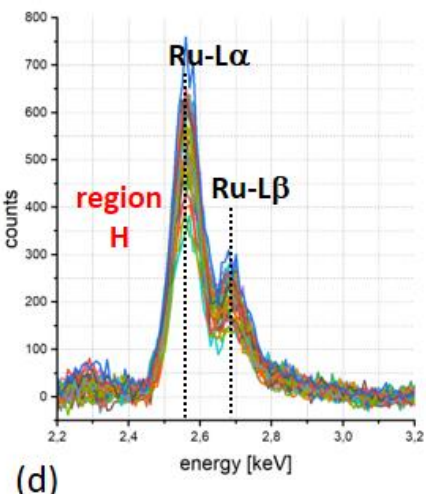

(d)

Figure S10. Ex situ EDXS spectra taken from as deposited and differently dosed purification experiments as specified by the legend. Here, ex situ means that fabrication and purification was performed in the main DBM instrument, while EDXS is performed in another instruments to check on possible ambient influences and to confirm the found trends by a different instrumentation. As for Figure 3 in the main manuscript, we here present the three main regions $(\mathrm{L}, \mathrm{M}, \mathrm{H})$ in more detail in the lower row. Particularly relevant is the $\mathrm{L}$ region where the peak position shifts to lower values for higher purification doses in agreement with the expected peak positions for $\mathrm{C}$ and $\mathrm{Ru}-\mathrm{M}$. The transition again indicates the shift from carbon dominated towards Ru dominated with higher doses. The exact evolution can be found in the following figure. 


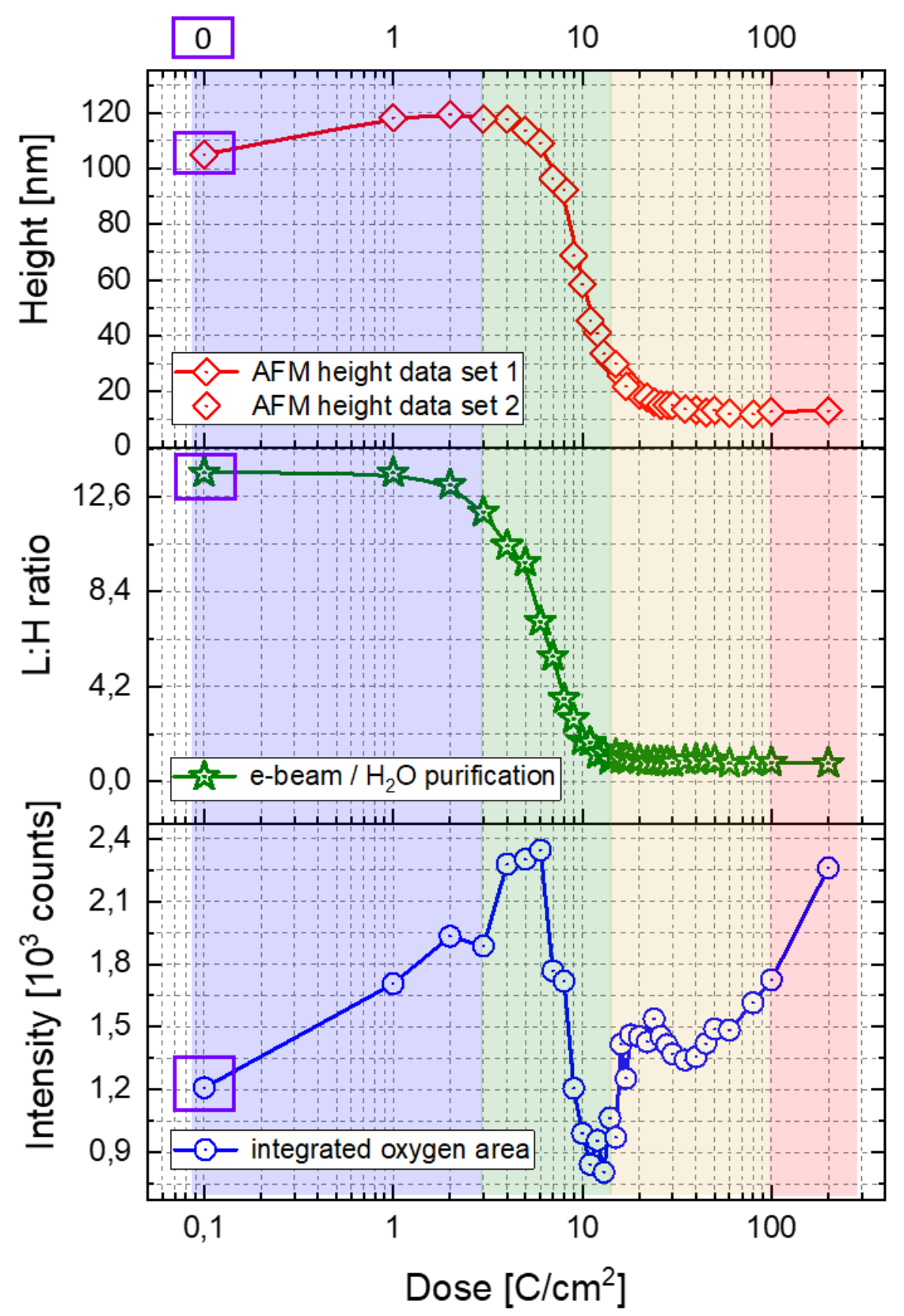

Figure S11. Dose dependent evolution of the L:H ratio (green stars) and the oxygen intensity (blue circles) based on the ex situ data shown in the previous supporting figure S10. The red diamonds at the top are again AFM data for full correlation. When comparing to Figure 4 of the main manuscript, it becomes evident, that ex situ data reveal a very similar behaviour. At low doses, the L:H ratio as a measure for the incorporated carbon does not change (central panel), while oxygen increases (bottom panel). Afterwards, carbon removal sets in together with the volume loss and a decaying oxygen intensity. After that process is widely completed, however, oxygen rises again, while L:H intensity ratios indicate removal of last carbon remaining. In this experimental series, we doubled the final doses from $100 \mathrm{C} / \mathrm{cm}^{2}$ to $200 \mathrm{C} / \mathrm{cm}^{2}$. The main effect, however, is the ongoing oxidation accompanied by a small volume and roughness increase (the latter can be seen in Figure 2 of the main manuscript). Note the logarithmic abscissa for the dose and that as-deposited values at the very left are emphasized by purple frames to visualize the evolution. 


\section{Structural Details via TEM}

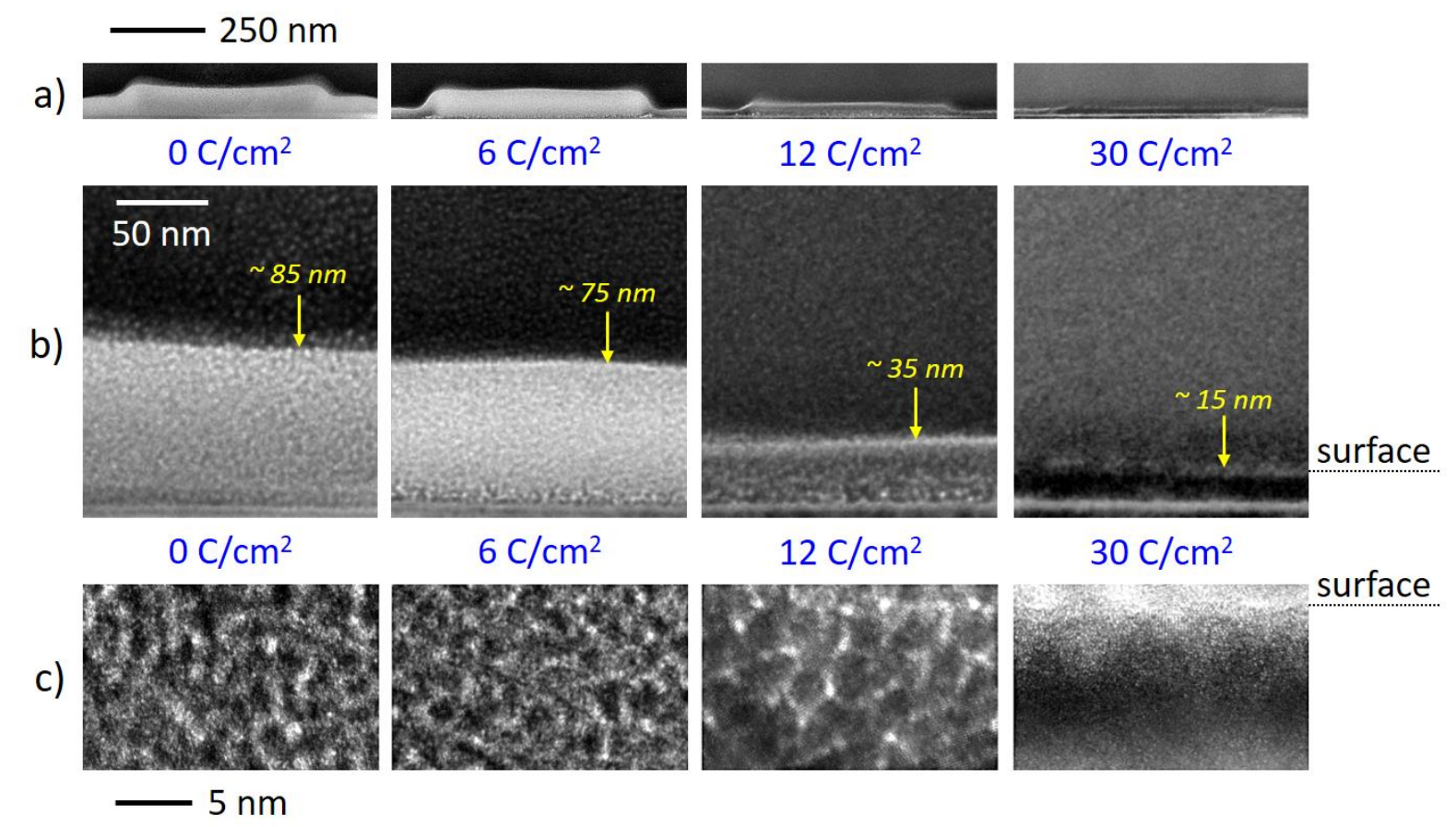

Figure S12. Structural evolution during e-beam $/ \mathrm{H}_{2} \mathrm{O}$ purification via transmission electron microscopy (TEM). (a) shows a cross sectional overview comparison from as-deposited $\left(0 \mathrm{C} / \mathrm{cm}^{2}\right)$ and differently purified structures (see blue doses underneath). (b) shows an in scale comparison of central regions in (a), where the fast height decay and structural changes become evident. The latter is shown in more detail in (c) where strongest changes are found for $6 \mathrm{C} / \mathrm{cm}^{2} \rightarrow 12 \mathrm{C} / \mathrm{cm}^{2}$ by means of clearly larger grain sizes, and for $12 \mathrm{C} / \mathrm{cm}^{2} \rightarrow 30 \mathrm{C} / \mathrm{cm}^{2}$ by the formation of a dense Ru film. Please note the increasingly darker character of the Ru layer for increasing doses (b), which reflects the increasing metallic density leading to less transmitted electrons. In (b) there is also a bright, thin line at the bottom, which is the lighter, $3 \mathrm{~nm}$ thick $\mathrm{SiO}_{2}$ layer of the substrate. ${ }^{\mathrm{SI} 2}$ 


\section{Fit of ESD From $(\text { EtCp })_{2}$ Ru Multilayer Films}

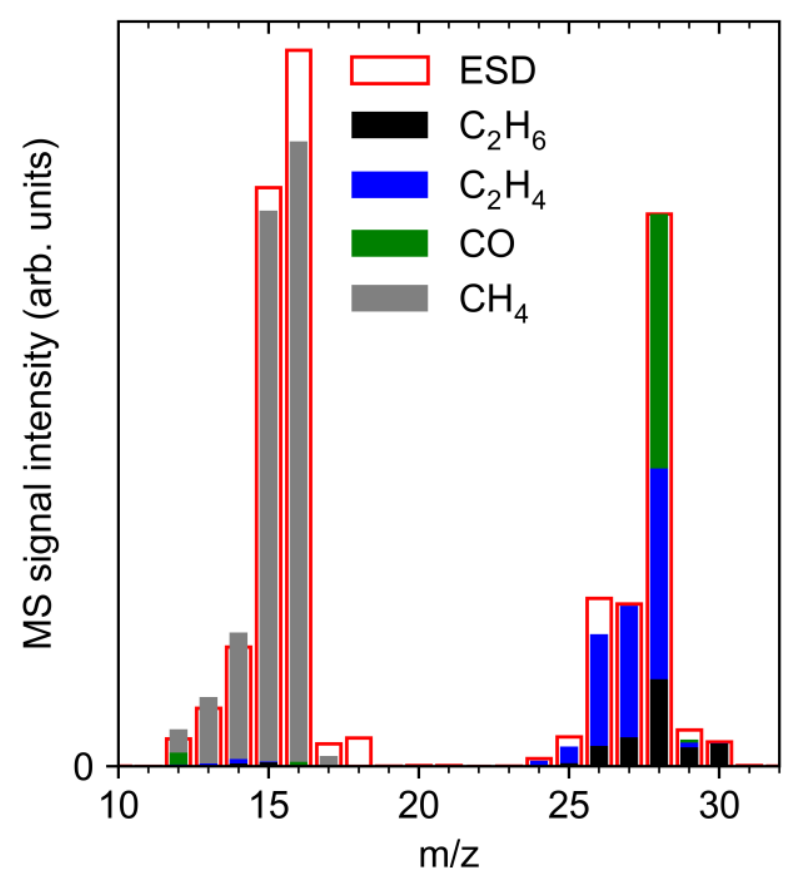

Figure S13. Fit of experimental ESD data acquired from a 13-20 ML (EtCp $)_{2} \mathrm{Ru}$ film during electron exposure at $\mathrm{E}_{0}=31 \mathrm{eV}$ (red frame, see also Figure 6(c)) with reference mass spectra of ethane $\left(\mathrm{C}_{2} \mathrm{H}_{6}\right)$, ethene $\left(\mathrm{C}_{2} \mathrm{H}_{4}\right)$, carbon monoxide $(\mathrm{CO})$, and methane $\left(\mathrm{CH}_{4}\right)$ taken from the NIST database. ${ }^{\mathrm{SI} 3}$

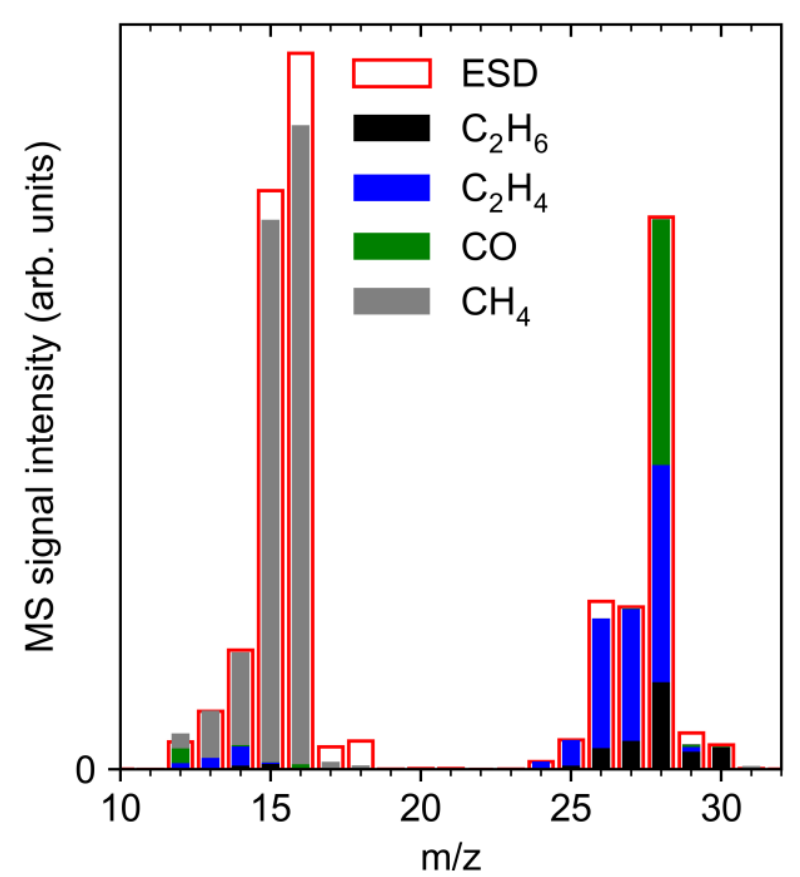

Figure S14. Fit of experimental ESD data acquired from a 13-20 ML (EtCp $)_{2} \mathrm{Ru}$ film during electron exposure at $\mathrm{E}_{0}=31 \mathrm{eV}$ (red frame, see also Figure 6(c)) with reference mass spectra of ethane $\left(\mathrm{C}_{2} \mathrm{H}_{6}\right)$, ethene $\left(\mathrm{C}_{2} \mathrm{H}_{4}\right)$, carbon monoxide $(\mathrm{CO})$, and methane $\left(\mathrm{CH}_{4}\right)$ acquired with the same QMS as the ESD data. 


\section{Gas Phase Mass Spectrum of $(\mathrm{EtCp})_{2} \mathrm{Ru}$}
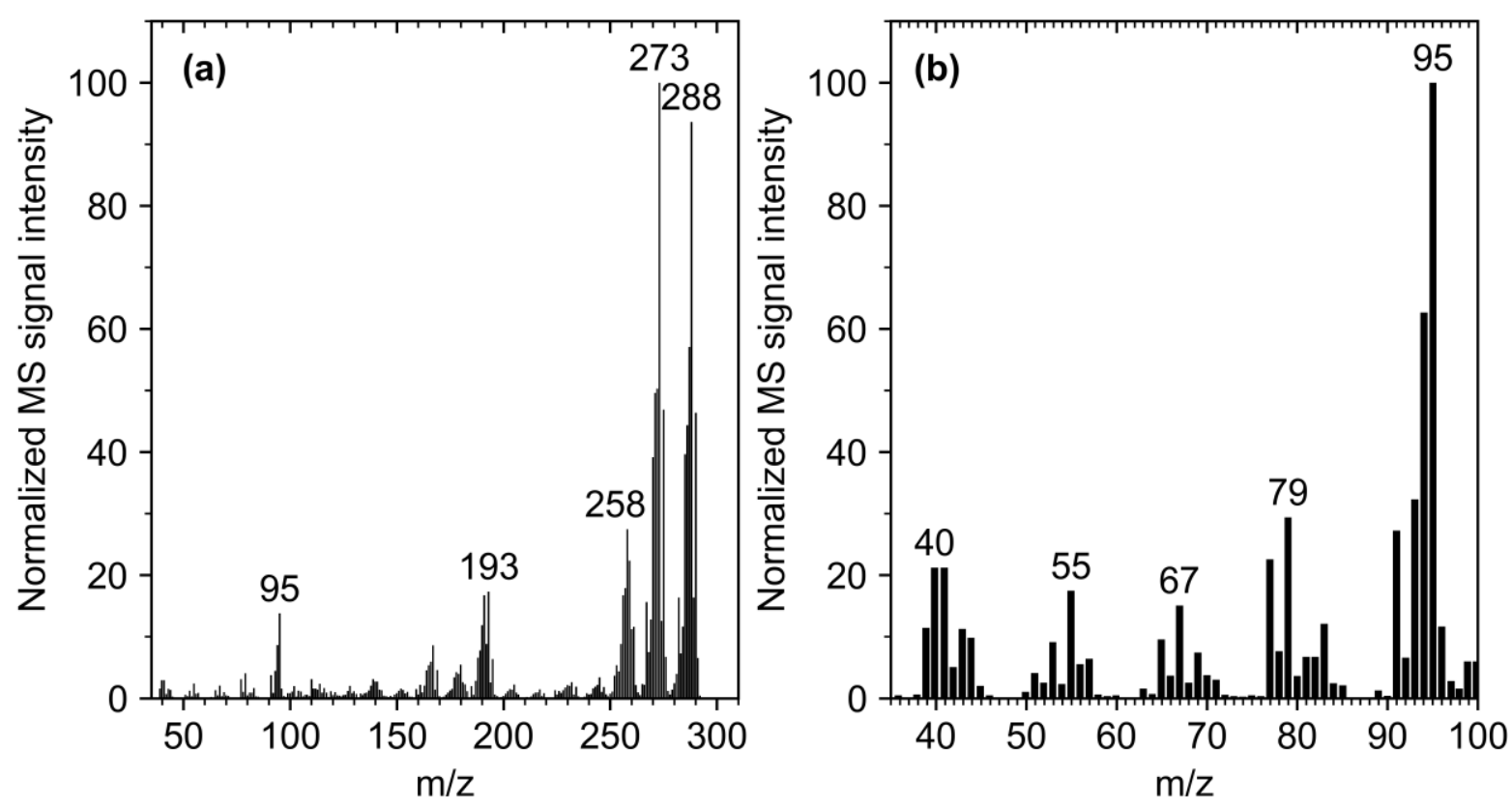

Figure S15. Sector mass scan of (EtCp) $)_{2}$ Ru recorded (a) over the full mass range showing signals (i.e. up to $\mathrm{m} / \mathrm{z} 300$ ) and (b) up to $\mathrm{m} / \mathrm{z} 100$ for a direct comparison with the QMS inlet spectrum shown in Fig. 1. The most intense signals in each signal group are annotated with the respective $\mathrm{m} / \mathrm{z}$ values. 
Kinetics of Electron-Induced $(\mathrm{EtCp})_{2} \mathrm{Ru}$ Decomposition at $\mathrm{E}_{0}=31 \mathrm{eV}$

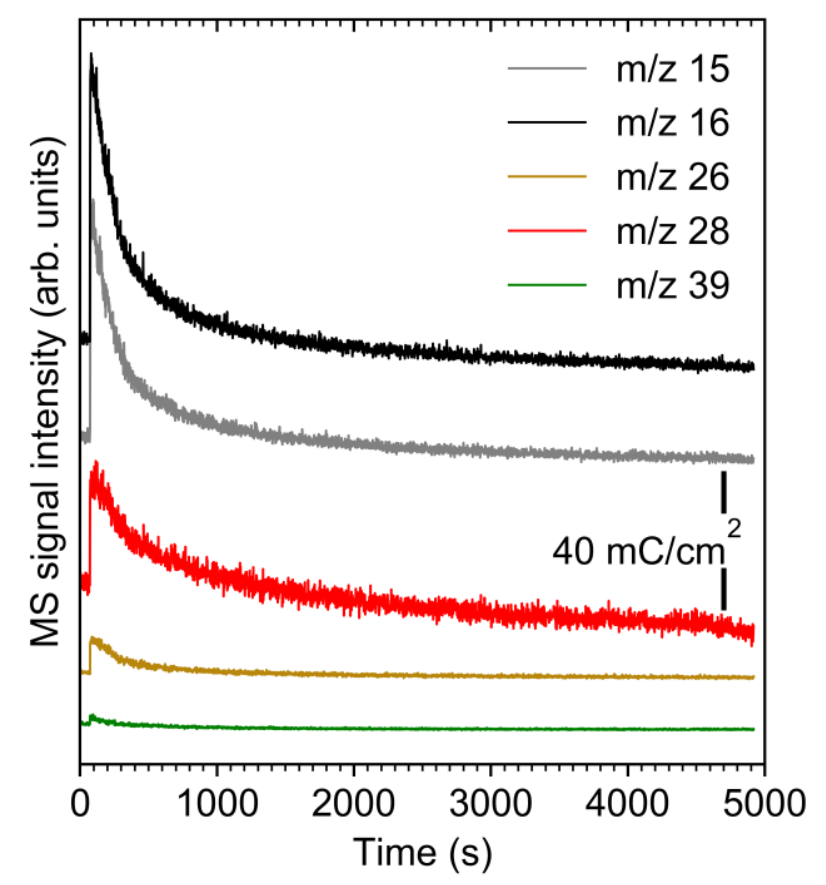

Figure S16. Electron-stimulated desorption obtained during electron exposure $\left(\mathrm{E}_{0}=31 \mathrm{eV}\right.$, electron dose: $\left.40 \mathrm{mC} / \mathrm{cm}^{2}\right)$ of a $13-20 \mathrm{ML}(\mathrm{EtCp})_{2} \mathrm{Ru}$ film held at $110 \mathrm{~K}$. The displayed $\mathrm{m} / \mathrm{z}$ ratios are characteristic of desorption of $\mathrm{CH}_{4}{ }^{+\bullet}(\mathrm{m} / \mathrm{z} 16), \mathrm{CH}_{3}{ }^{+}(\mathrm{m} / \mathrm{z} 15), \mathrm{CO}^{+} / \mathrm{C}_{2} \mathrm{H}_{4}{ }^{+} / \mathrm{C}_{2} \mathrm{H}_{6}\left(\mathrm{C}_{2} \mathrm{H}_{4}{ }^{+}\right.$fragment) $(\mathrm{m} / \mathrm{z} 28), \mathrm{C}_{2} \mathrm{H}_{2}{ }^{+*}(\mathrm{~m} / \mathrm{z} 26)$, and of fragments containing the cyclopentadienyl ring $(\mathrm{m} / \mathrm{z} 39)$. 


\section{Water-Assisted Purification Sequence in Absence of Deposit}

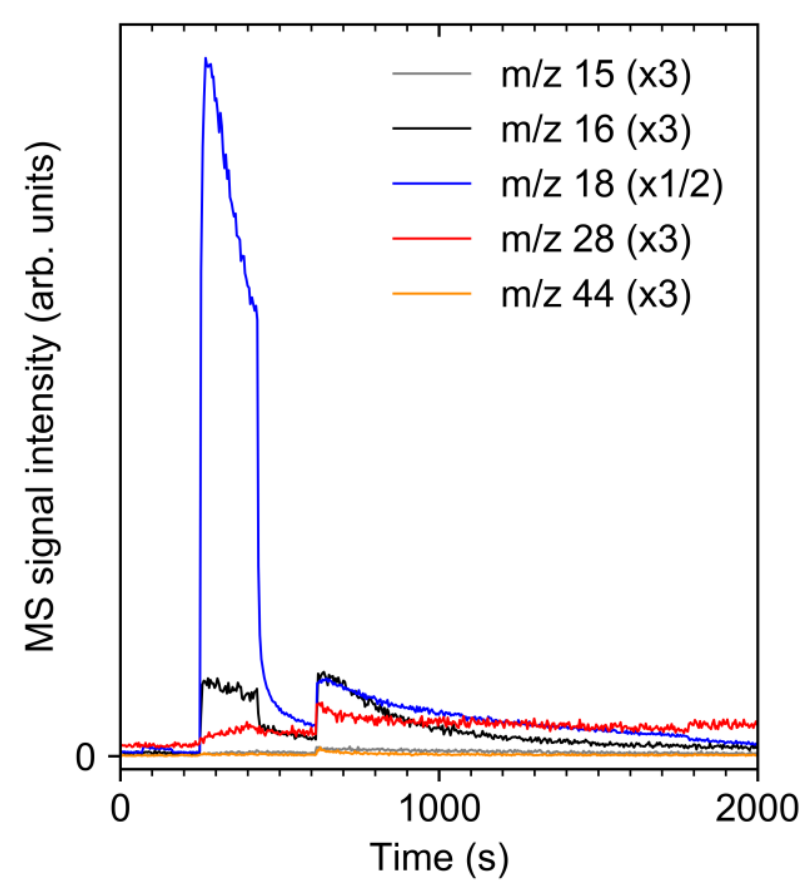

Figure S17. Isothermal and electron-stimulated desorption spectrum (IDS and ESD) recorded during a water-assisted purification model experiment as shown in Figure 7 but without the presence of a $(\mathrm{EtCp})_{2} \mathrm{Ru}$ deposit. A short electron exposure $\left(60-180 \mathrm{~s}, 31 \mathrm{eV}, 2 \mathrm{mC} / \mathrm{cm}^{2}\right)$ was applied at the beginning of the purification experiment to verify that no ESD occurred. A total amount of $40-80 \mathrm{ML} \mathrm{H}_{2} \mathrm{O}$ was then dosed onto the Ta sheet held at $110 \mathrm{~K}(220-480 \mathrm{~s})$. Finally, a further electron exposure (600-1800 s, $31 \mathrm{eV}, 20 \mathrm{mC} / \mathrm{cm}$ ) was performed at the same temperature. 


\section{Post-purification TDS}

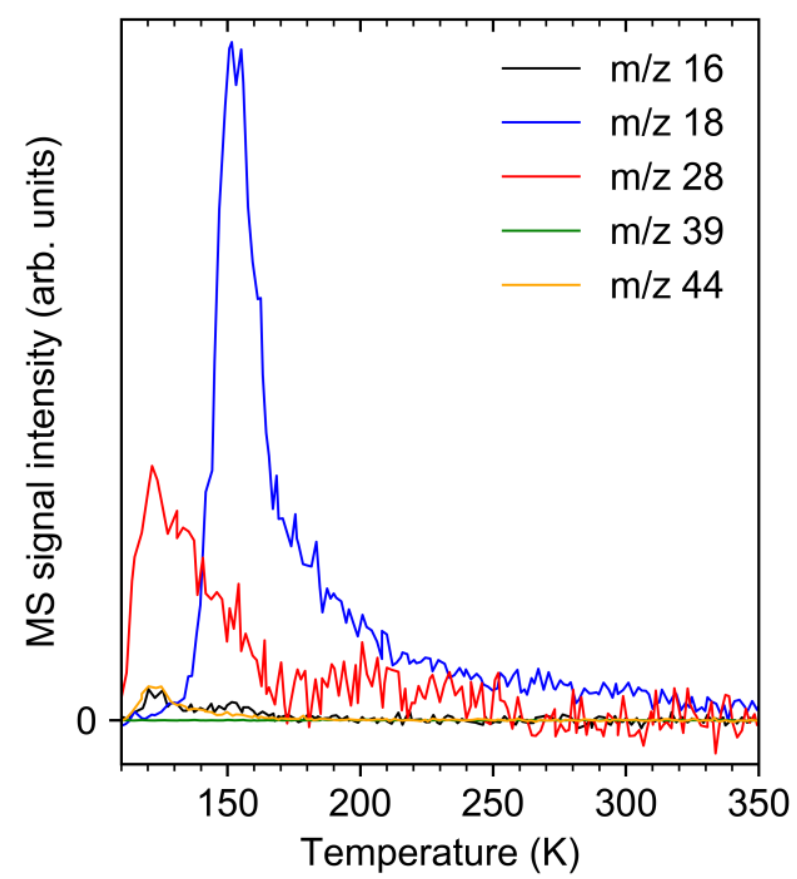

Figure S18. Thermal desorption spectrum recorded at the end of a water-assisted purification cycle employing a 40-80 ML water film performed on a deposit produced from (EtCp $)_{2} \mathrm{Ru}$. 


\section{Water-Assisted Purification Without Annealing, Without First Exposure Step}

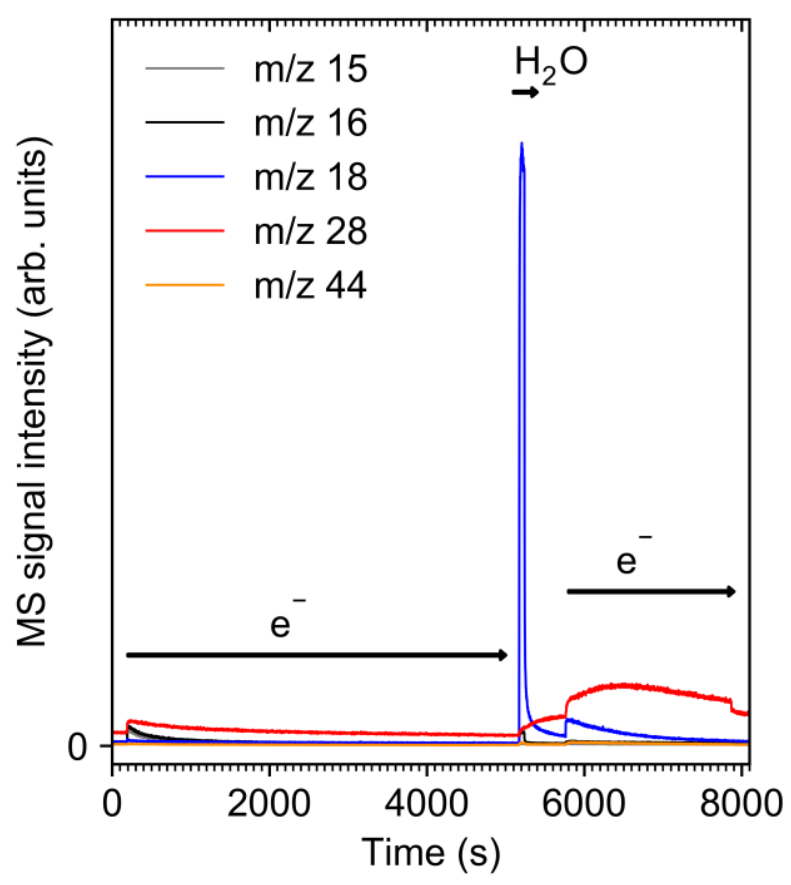

Figure S19. Isothermal and electron-stimulated desorption spectrum (IDS and ESD) obtained during formation (200-4900 s, $\left.40 \mathrm{mC} / \mathrm{cm}^{2}\right)$ and water-assisted purification (5000-7900 s including electron exposure of $\left.20 \mathrm{mC} / \mathrm{cm}^{2}\right)$ of a $(\mathrm{EtCp})_{2} \mathrm{Ru}$ deposit produced from a 13-20 ML film of $(\mathrm{EtCp})_{2} \mathrm{Ru}$. The deposit was not annealed to $450 \mathrm{~K}$ before water-assisted purification took place. Electron exposure $\left(\mathrm{e}^{-}\right)$ and $\mathrm{H}_{2} \mathrm{O}$ dosing $\left(\mathrm{H}_{2} \mathrm{O}\right)$ steps are marked. Electron irradiation was carried out at an incident electron energy of $\mathrm{E}_{0}=31 \mathrm{eV}$. 


\section{Comparison of DMB and UHV Conditions}

Table S1. Comparison of experimental conditions in the DBM and in the surface science study in UHV during water-assisted purification of deposits produced by electron-induced decomposition of $(\mathrm{EtCp})_{2} \mathrm{Ru}$.

\begin{tabular}{|c|c|c|}
\hline & DBM (LP mode) & UHV \\
\hline \multicolumn{3}{|l|}{ Sample } \\
\hline Sample thickness & 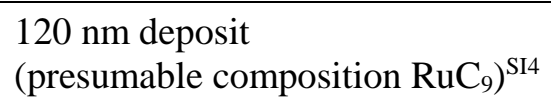 & $\begin{array}{l}13-20 \mathrm{~nm} \\
\text { (pristine precursor, } \mathrm{RuC}_{14} \text { ) }\end{array}$ \\
\hline Sample dimension & $500 \times 500 \mathrm{~nm}^{2}$ pads & $5 \mathrm{~cm}^{2}$ continuous layer \\
\hline Number density of $\mathrm{C}$ & $\begin{array}{l}10^{18} \cdot \mathrm{cm}^{-2} \\
\left(\text { based on density } 3.2 \mathrm{~g} \cdot \mathrm{cm}^{-3}\right)^{a}\end{array}$ & $\begin{array}{l}5 \cdot 10^{16} \cdot \mathrm{cm}^{-2}-8 \cdot 10^{16} \cdot \mathrm{cm}^{-2} \\
\left(\text { based on density } 1.34 \mathrm{~g} \cdot \mathrm{cm}^{-3}\right)^{b}\end{array}$ \\
\hline \multicolumn{3}{|l|}{ Electron beam } \\
\hline Energy & $5 \mathrm{keV}$ & $31 \mathrm{eV}$ \\
\hline Beam current & $5.6 \mathrm{nA}=3.5 \cdot 10^{10} \mathrm{e}^{-} \cdot \mathrm{s}^{-1}$ & $30 \mu \mathrm{A} \cdot \mathrm{cm}^{-2}=1.9 \cdot 10^{14} \mathrm{e}^{-} \cdot \mathrm{s}^{-1} \cdot \mathrm{cm}^{-2}$ \\
\hline Beam size & Focused, $76 \mathrm{~nm}$ (diameter) & Broad, entire sample \\
\hline \multicolumn{3}{|l|}{ Purification process } \\
\hline Temperature & $\sim 300 \mathrm{~K}$ & $110 \mathrm{~K}$, anneal to $450 \mathrm{~K}$ \\
\hline Process & $\begin{array}{l}\text { Continuous, } \\
\text { simultaneous } \mathrm{e}^{-} \text {and } \mathrm{H}_{2} \mathrm{O} \text { flux }\end{array}$ & $\begin{array}{l}24 \text { cycles of dosing } \mathrm{H}_{2} \mathrm{O} \text { and } \\
\text { subsequent } \mathrm{e}^{-} \text {irradiation at } 110 \mathrm{~K} \\
\text { followed by annealing to } 450 \mathrm{~K}\end{array}$ \\
\hline $\mathrm{H}_{2} \mathrm{O}$ flux & $\begin{array}{l}2 \cdot 10^{20} \mathrm{~s}^{-1} \mathrm{~cm}^{-2} \\
\text { (at partial pressure of } 50 \mathrm{~Pa} \text {, } \\
\text { sticking coefficient unknown) }\end{array}$ & \\
\hline $\mathrm{H}_{2} \mathrm{O}$ dose & & $\begin{array}{l}24 \times 8 \cdot 10^{16} \mathrm{~cm}^{-2}=1.9 \cdot 10^{18} \mathrm{~cm}^{-2} \\
(40-80 \mathrm{ML} \text { per cycle, assuming } \\
\text { unit sticking coefficient })^{c}\end{array}$ \\
\hline Electron flux & $8 \cdot 10^{20} \mathrm{e}^{-} \mathrm{s}^{-1} \mathrm{~cm}^{-2 \mathrm{~d}}$ & $1.9 \cdot 10^{14} \mathrm{e}^{-} \cdot \mathrm{s}^{-1} \cdot \mathrm{cm}^{-2}$ \\
\hline Electron exposure & $\begin{array}{l}\text { Complete removal of } \mathrm{C} \text { within } \\
30 \mathrm{C} \mathrm{cm}^{-2}=2 \cdot 10^{20} \mathrm{e}^{-} \mathrm{cm}^{-2 \mathrm{~d}} \\
\text { Per pad of } 500 \times 500 \mathrm{~nm}^{2}: \\
4.7 \cdot 10^{11} \mathrm{e}^{-} \mathrm{pad}^{-1} \\
\text { Removal of } 60 \% \mathrm{C} \text { within } \\
\sim 8 \mathrm{C} \mathrm{cm}^{-2}=5.4 \cdot 10^{19} \mathrm{e}^{-} \mathrm{cm}^{-2}\end{array}$ & $\begin{array}{l}\text { Removal of } 60 \% \mathrm{C} \text { within } \\
24 \times 1.25 \cdot 10^{17} \mathrm{e}^{-} \mathrm{cm}^{-2} \\
0.48 \mathrm{C} \mathrm{cm}^{-2}=3 \cdot 10^{18} \mathrm{e}^{-} \mathrm{cm}^{-2}\end{array}$ \\
\hline Limiting factor & Electrons $^{\mathrm{e}}$ & Electrons $^{\mathrm{f}}$ \\
\hline Depth profile & Bottom-up & unknown \\
\hline
\end{tabular}

a Density calculated for the composition $\mathrm{RuC}_{9}{ }^{\mathrm{SI}}$ as the average of the densities of $12.1 \mathrm{~g} \cdot \mathrm{cm}^{-3}$ for $\mathrm{Ru}$ and $2.2 \mathrm{~g} \cdot \mathrm{cm}^{-3}$ for $\mathrm{C}$ (graphite) (II $^{\mathrm{S}}$

b density of $(\mathrm{EtCp})_{2} \mathrm{Ru}$ at $15^{\circ} \mathrm{C}$ according to supplier data ${ }^{\mathrm{SI}}$

c calculated based on effective diameter of an $80 \mathrm{ML} \mathrm{H}_{2} \mathrm{O}$ layer, see text.

$\mathrm{d}$ calculated from beam current and beam diameter assuming constant current density over the beam area.

e According to reference SI2

f See Section 3.3 of main manuscript. 


\section{References}

(SI1) Drouin, D.; Couture, A. R.; Joly, D.; Tastet, X.; Aimez, V.; Gauvin, R. CASINO V2.42—A Fast and Easy-to-Use Modeling Tool for Scanning Electron Microscopy and Microanalysis Users. Scanning 2007, 29 (3), 92-101.

(SI2) Geier, B.; Gspan, C.; Winkler, R.; Schmied, R.; Fowlkes, J. D.; Fitzek, H.; Rauch, S.; Rattenberger, J.; Rack, P. D.; Plank, H. Rapid and Highly Compact Purification for Focused Electron Beam Induced Deposits: A Low Temperature Approach Using Electron Stimulated $\mathrm{H}_{2} \mathrm{O}$ Reactions. J. Phys. Chem. C 2014, 118 (25), 14009-14016.

(SI3) NIST Mass Spec Data Center. Mass Spectra. In NIST Chemistry WebBook, NIST Standard Reference Database Number 69; Linstrom, P. J.; Mallard, W. G., Eds.; National Institute of Standards and Technology: Gaithersburg MD, U.S.A., 2020.

(SI4) Noh, J. H.; Stanford, M. G.; Lewis, B. B.; Fowlkes, J. D.; Plank, H.; Rack, P. D. Nanoscale Electron Beam-Induced Deposition and Purification of Ruthenium for Extreme Ultraviolet Lithography Mask Repair. Appl. Phys. A 2014, 117 (4), 1705-1713.

(SI5) CRC Handbook of Chemistry and Physics: A Ready-Reference Book of Chemical and Physical Data, 77th ed.; Lide, D. R., Frederikse,H. P. R., Eds.; CRC Press: Boca Raton, FL, 1996.

(SI6) https://www.strem.com/catalog/v/44-0040/59/ruthenium_32992-96-4 (retrieved January 10, 2020). 